Pathophysiology of Haemostasis and Thrombosis
Pathophysiol Haemost Thromb 2003/04;33:184-191 Received: July 26, 2004

DOI: $\underline{10.1159 / 000081506}$

\title{
Ecarin Chromogenic Assay - A New Method for Quantitative Determination of Direct Thrombin Inhibitors Like Hirudin
}

\author{
U. Lange ${ }^{a}$ G. Nowak ${ }^{b}$ E. Bucha ${ }^{a}$

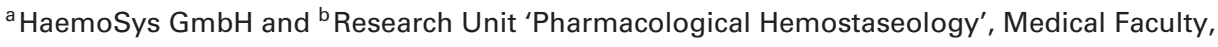 \\ Friedrich Schiller University, Jena, Germany
}

\section{Key Words}

Hirudin - Thrombin inhibitor - Ecarin chromogenic

assay $\cdot$ Ecarin clotting time $\cdot$ Argatroban

\begin{abstract}
A new sensitive and precise method for quantitative determination of direct thrombin inhibitors is described, the ecarin chromogenic assay (ECA). Ecarin is used as the specific prothrombin-activating principle. The cleavage of a chromogenic substrate by meizothrombin is inhibited in a concentration-dependent fashion by direct thrombin inhibitors. For the ECA, the linear measuring range is about $0.1-3.0 \mu \mathrm{g}$ hirudin $/ \mathrm{ml}$ plasma. Coefficients of variations between 2.3 and $4 \%$ over the whole concentration range were achieved. The ECA has proved to be more sensitive than the compared tests (ecarin clotting time and a thrombin-based chromogenic assay); a detection limit of $0.011 \mu \mathrm{g}$ hirudin $/ \mathrm{ml}$ and a quantitation limit of $0.032 \mu \mathrm{g}$ hirudin $/ \mathrm{ml}$ were calculated. The ECA is independent of the variations of the coagulation variables fibrinogen and prothrombin. Neither heparin nor oral anticoagulants interfere with the ECA.
\end{abstract}

Copyright $\odot 2004$ S. Karger AG, Base

\section{Introduction}

Natural or synthetic direct inhibitors of thrombin, the key enzyme in blood coagulation, have been increasingly used for the prophylaxis and treatment of thromboembolic disorders. Recombinant hirudin, a highly specific, tight-binding thrombin inhibitor, was the first direct thrombin inhibitor introduced. Because of its narrow therapeutic range, clinical monitoring of hirudin is necessary to avoid inadequate anticoagulation due to underdosage and in order to avoid overdosage being accompanied by severe bleeding complications. Different methods for the determination of direct thrombin inhibitors, especially of hirudin, are in use. Global clotting tests like activated partial thromboplastin time (aPTT), thrombin time and variations thereof or activated coagulation time were investigated regarding their suitability in monitoring direct thrombin inhibitors like hirudin [1-5]. Immunological methods and chromogenic assays as well as special coagulation assays, e.g. the ecarin clotting time (ECT), were developed for the monitoring of anticoagulant therapy [6-16]. The suitability of these methods for the determination of hirudin and other direct thrombin inhibitors, their advantages and drawbacks are discussed in detail by Nowak [17] and Hafner et al. [18]. These authors recommend particularly the ECT and also chromogenic substrate assays as suitable for the monitoring of therapy with direct thrombin inhibitors.

Dr. Ute Lange

HaemoSys GmbH

Winzerlaer Strasse 2

DE-07745 Jena (Germany)

Tel. +49 36415083 21, Fax +49 36415083 01, E-Mail u.lange@haemosys.de
Fax +41613061234

E-Mailkarger@karger.ch_Accessible online at:

www.karger.com 


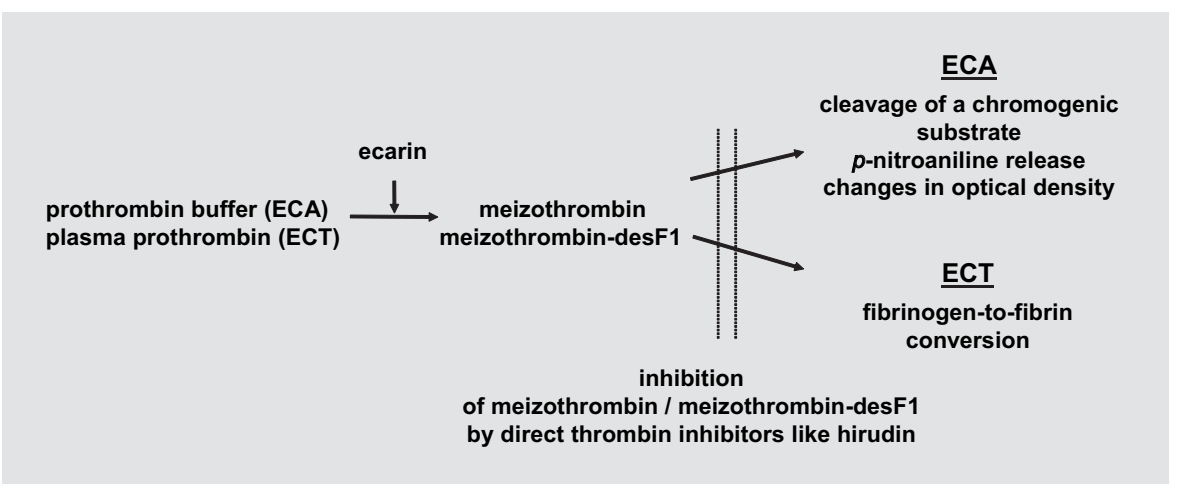

Fig. 1. Principle of measurement of ECA compared with ECT.

A new chromogenic assay based on the same principle as the ECT, the ecarin chromogenic assay (ECA), has been developed to preserve the advantages of the ECT and overcome the deficiencies of the methods for determination of direct thrombin inhibitors used so far.

\section{Materials and Methods}

The ECA-H HaemoSys ${ }^{\circledR}$ kit for quantitative determination of hirudin in plasma and the ECA-T HaemoSys ${ }^{\circledR}$ kit for quantitative determination of synthetic direct thrombin inhibitors in plasma are commercially available from HaemoSys $\mathrm{GmbH}$, Jena, Germany. The kits consist of human prothrombin containing ECA prothrombin buffer, the ECA-H or ECA-T substrate, containing a specific thrombin substrate, and the ECA ecarin reagent. Additionally, the kits include standards and controls: ECA-H standards, ECA-H controls and ECA-T standards, ECA-T controls, respectively. Pooled plasma of healthy volunteers $(n=10)$ was purchased from DRK-Blutspendedienst, Institut Gera, Gera, Germany. r-Hirudin, Refludan ${ }^{\circledR}$, was from Schering AG, Berlin, Germany. Argatroban, Novastan ${ }^{\circledR}$, was from Texas Biotechnology Corp., Houston, Tex., USA. Human factor-II-deficient plasma and ecarin were obtained from Loxo Ltd., Dossenheim, Germany. Unfractionated heparin (International Standard for Heparin, 82/502, 712 IU anti$\mathrm{IIa} / \mathrm{ml}$ ) was from the National Institute for Biological Standards and Control, Hertfordshire, UK. Human fibrinogen (Pg-, vWFand Fn-depleted) was purchased from Kordia bv, Leiden, Netherlands. Defibrinated plasma was made by heating pooled plasma for $4 \mathrm{~min}$ at $56^{\circ} \mathrm{C}$ followed by rapid cooling and centrifugation. The fibrinogen content of plasma was determined by conversion of fibrinogen to fibrin using thrombin, and by determination of the protein clot content using the Biuret method according to Ratnoff and Menzie [19].

As an alternative thrombin-based chromogenic test, the hirudin activity assay from Dade Behring (Dade Behring Vertriebs $\mathrm{GmbH}$ $\&$ Co., Schwalbach, Germany) was used. According to the instructions of the manufacturer, $25 \mu \mathrm{l}$ plasma sample and $50 \mu \mathrm{l}$ substrate reagent were mixed. Reaction was started by addition of $250 \mu \mathrm{l}$ thrombin reagent, and the change in optical density was measured at $405 \mathrm{~nm}$ for $1 \mathrm{~min}$. The test was performed at $37^{\circ} \mathrm{C}$ on a manual 4-channel coagulation analyzer TEChrom IV plus (Teco GmbH, Neufahrn, Germany).

Ecarin Chromogenic Assay
The ECT test was performed according to Nowak and Bucha [20] using a manual coagulometer (CL4; Behnk Elektronik GmbH \& Co. KG, Norderstedt, Germany).

The principle of measurement of the ECA is shown in figure 1. Similar to the ECT, the ECA is based on ecarin-induced prothrombin activation. In the ECT test, plasma prothrombin is used, whereas in the ECA, human prothrombin is contained in excessive amounts in the ECA prothrombin buffer HaemoSys. Unlike in the ECT test where the clotting activity of meizothrombin/meizothrombin-desF1 is measured, the amidolytic activity towards a chromogenic substrate is determined in the ECA by the measurement of $p$-nitroaniline release. Changes in optical density are recorded at $405 \mathrm{~nm}$. The time is stopped when a threshold of 0.1 absorption units is reached (ECA reaction time).

Reagents for the ECA were dissolved according to the instructions of the manufacturer. The test procedure for ECA HaemoSys was as follows:

$100 \mu 1$ ECA prothrombin buffer

prewarmed in the coagulation analyzer at $37^{\circ} \mathrm{C}$

$+25 \mu$ plasma sample

room temperature

$+25 \mu 1$ ECA substrate

prewarmed in the coagulation analyzer at $37^{\circ} \mathrm{C}$

incubation for $1 \mathrm{~min}$ at $37^{\circ} \mathrm{C}$

$+50 \mu \mathrm{l} \mathrm{ECA}$ ecarin reagent

start of measurement

For the determination of hirudin in plasma, the ECA-H substrate and ECA-H method were used, whereas for the determination of the synthetic direct thrombin inhibitor argatroban, the ECAT substrate and ECA-T method were used. ECA was measured using the 2-channel manual coagulation analyzer Coatron M2 and the 4-channel coagulation analyzer TEChrom IV plus (both Teco $\mathrm{GmbH}$, adapted for ECA-H and ECA-T), respectively.

\section{Results}

To prepare an ECA reference curve, pooled plasma of healthy volunteers was spiked with known amounts of hirudin. An example curve for the 2-channel coagulation analyzer Coatron M2 is given in figure 2. The reference 
Fig. 2. Reference curve of quantitative determination of hirudin using ECA. Data were acquired on Coatron $\mathrm{M} 2 ; \mathrm{n}=30$, mean values and SD are given.

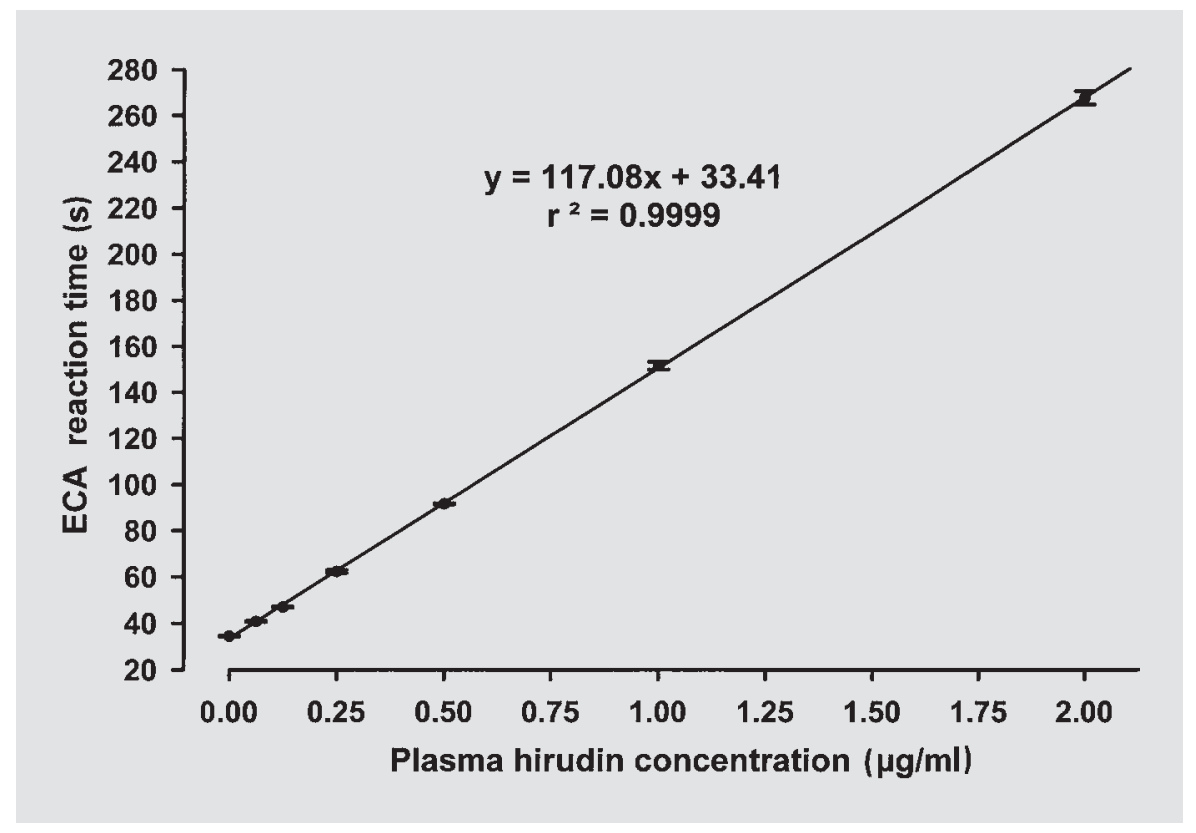

Table 1. Imprecision data of ECA compared with a thrombin-based chromogenic test and ECT

\begin{tabular}{|c|c|c|c|c|c|c|}
\hline & \multicolumn{6}{|c|}{ Added amount of hirudin, $\mu \mathrm{g} / \mathrm{ml}$} \\
\hline & 0.062 & 0.125 & 0.250 & 0.500 & 1.000 & 2.000 \\
\hline Number of replicates & 30 & 30 & 30 & 30 & 30 & 30 \\
\hline \multicolumn{7}{|l|}{ Thrombin-based chromogenic test } \\
\hline Mean, $\mu \mathrm{g} / \mathrm{ml}$ & & & 0.213 & 0.504 & 1.048 & 1.980 \\
\hline $\mathrm{SD}, \mu \mathrm{g} / \mathrm{ml}$ & & & 0.031 & 0.042 & 0.070 & 0.094 \\
\hline $\mathrm{CV}, \%$ & & & 14.4 & 8.4 & 6.7 & 4.8 \\
\hline Recovery, \% & & & 85.2 & 100.8 & 104.8 & 99.0 \\
\hline Detection limit, $\mu \mathrm{g} / \mathrm{ml}$ & 0.199 & & & & & \\
\hline Quantitation limit, $\mu \mathrm{g} / \mathrm{ml}$ & 0.575 & & & & & \\
\hline \multicolumn{7}{|l|}{ ECT test } \\
\hline Mean, $\mu \mathrm{g} / \mathrm{ml}$ & 0.073 & 0.133 & 0.269 & 0.543 & 1.088 & 2.080 \\
\hline $\mathrm{SD}, \mu \mathrm{g} / \mathrm{ml}$ & 0.012 & 0.017 & 0.023 & 0.042 & 0.067 & 0.111 \\
\hline $\mathrm{CV}, \%$ & 16.7 & 12.8 & 8.6 & 7.7 & 6.1 & 5.3 \\
\hline Recovery, \% & 117.7 & 106.4 & 107.6 & 108.6 & 108.8 & 104.0 \\
\hline Detection limit, $\mu \mathrm{g} / \mathrm{ml}$ & 0.046 & & & & & \\
\hline Quantitation limit, $\mu \mathrm{g} / \mathrm{ml}$ & 0.138 & & & & & \\
\hline \multicolumn{7}{|l|}{$E C A$} \\
\hline Mean, $\mu \mathrm{g} / \mathrm{ml}$ & 0.063 & 0.126 & 0.232 & 0.503 & 1.020 & 1.991 \\
\hline $\mathrm{SD}, \mu \mathrm{g} / \mathrm{ml}$ & 0.004 & 0.005 & 0.009 & 0.016 & 0.033 & 0.045 \\
\hline $\mathrm{CV}, \%$ & 6.2 & 4.0 & 3.9 & 3.2 & 3.2 & 2.3 \\
\hline Recovery, \% & 101.6 & 100.8 & 92.8 & 100.6 & 102.0 & 99.6 \\
\hline Detection limit, $\mu \mathrm{g} / \mathrm{ml}$ & 0.011 & & & & & \\
\hline Quantitation limit, $\mu \mathrm{g} / \mathrm{ml}$ & 0.032 & & & & & \\
\hline
\end{tabular}

Hirudin was determined using a thrombin-based chromogenic test on TEChrom IV plus coagulation analyzer, ECT test on CL4 coagulometer, and ECA on TEChrom IV plus coagulation analyzer. 
Fig. 3. Reproducibility of ECA. Data were acquired on Coatron M2; values of reference curves determined on 24 different days using 6 different reagent batches (O) and the mean values of it with $\operatorname{SD}(\bullet)$.
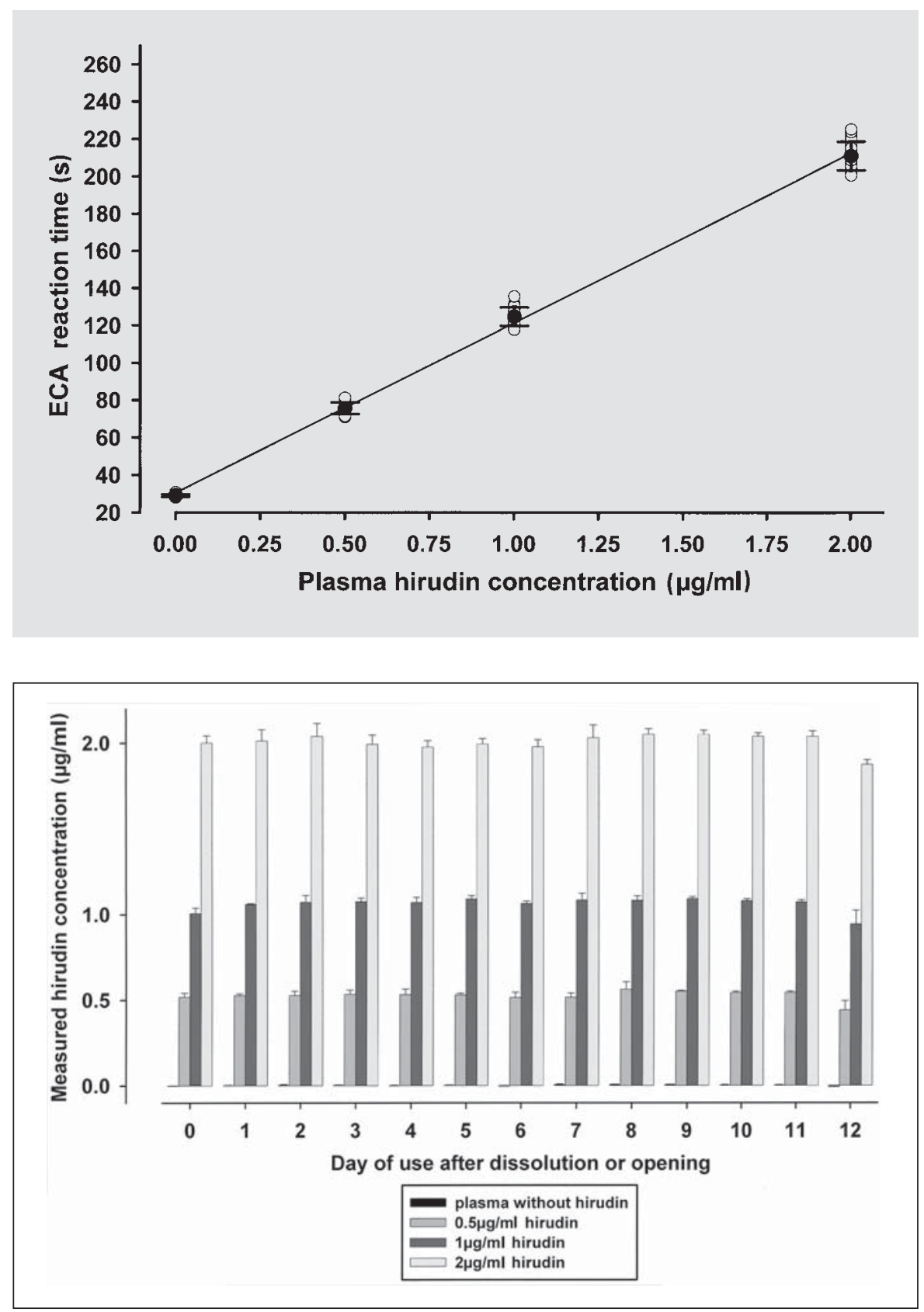

Fig. 4. Stability of ECA reagents in use. Data were acquired on TEChrom IV plus; mean values and SD of 5 different sets of reagents, ECA prothrombin buffer, ECA-H substrate and ECA ecarin reagent are given. curve shows a clear linearity between ECA reaction time and inhibitor concentration over a broad concentration range. Linearity was observed at up to $3 \mu \mathrm{g} / \mathrm{ml}$ (data not shown). Imprecision data for hirudin determination in plasma using the manual 4-channel coagulation analyzer TEChrom IV plus are given in table 1. Data calculated for the ECA are compared with those obtained by the thrombin-based chromogenic assay using the same coagulation analyzer and ECT, respectively. Accuracy is ex- pressed as percent recovery. The detection limit is expressed as $3.3 \times \mathrm{SD} / \mathrm{S}$, the quantitation limit as $10 \times$ $\mathrm{SD} / \mathrm{S}$, where SD represents the standard deviation of the blank $(n=30)$ given in seconds and $\mathrm{S}$ represents the slope of the reference curve. Using ECA, coefficients of variation (CV) between 2.3 and $4.0 \%$, and $6.2 \%$ for the low plasma hirudin concentration of $0.062 \mu \mathrm{g} / \mathrm{ml}$, were achieved. With ECT, CV between 5.3 and $8.6 \%$, and in the lower range $12.8 \%$ for $0.125 \mu \mathrm{g} / \mathrm{ml}$ and $16.7 \%$ for 


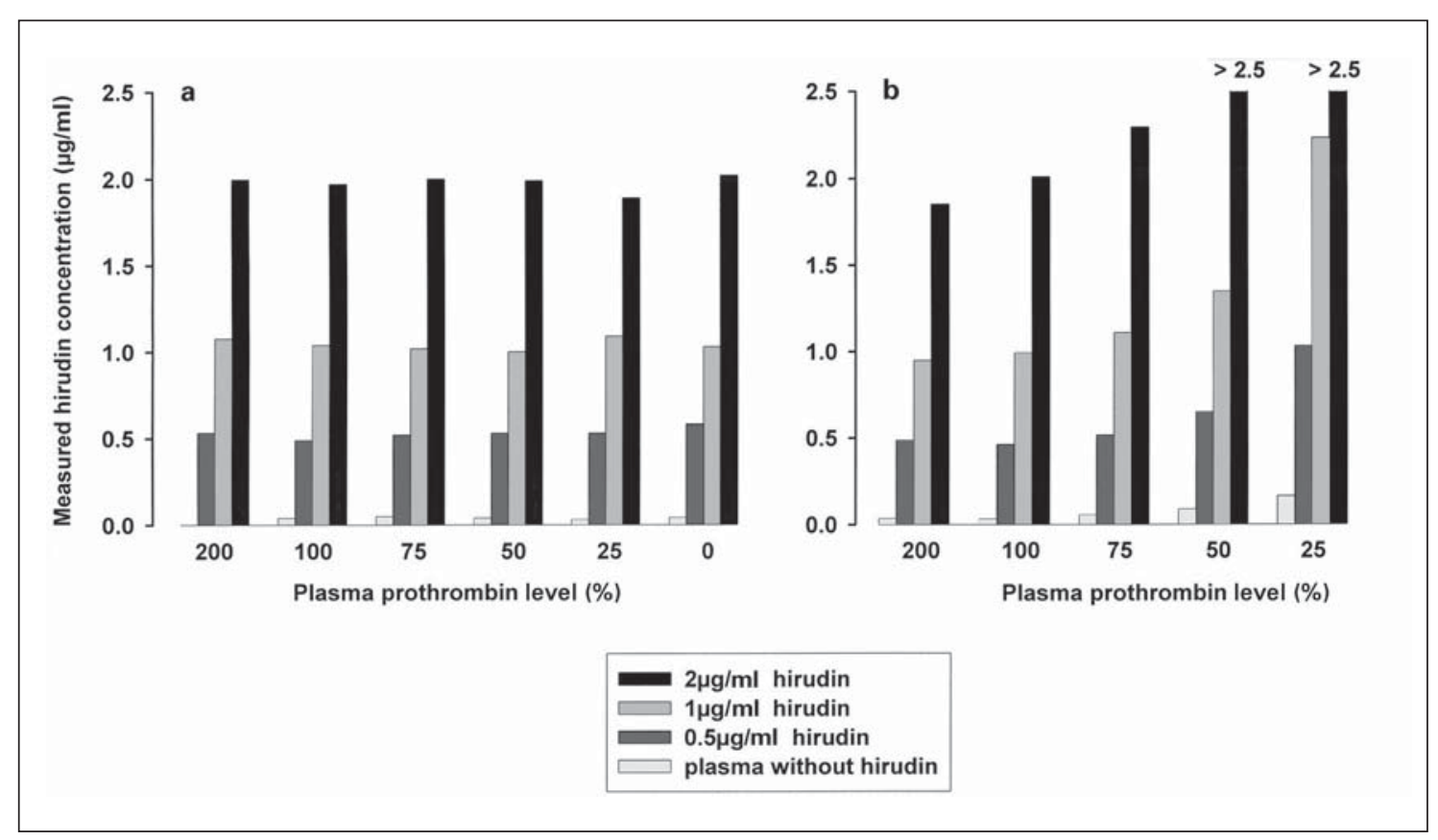

Fig. 5. Influence of the plasma prothrombin level on hirudin determination using ECA (a) and ECT (b). Data were acquired on TEChrom IV plus; $\mathrm{n}=3$.

$0.062 \mu \mathrm{g} / \mathrm{ml}$, were determined. Using the thrombin-based chromogenic assay, CV between 4.8 and $14.4 \%$ were obtained. For this test, a detection limit of $0.199 \mu \mathrm{g} / \mathrm{ml}$ was calculated; therefore, the hirudin concentrations of 0.125 and $0.062 \mu \mathrm{g} / \mathrm{ml}$ were not measured (table 1 ).

The reproducibility of ECA was determined by measuring hirudin reference curves on 24 days within 2 months using different batches of reagents. Figure 3 shows that there is a very good day-to-day and inter-batch reproducibility.

The stability of the ECA reagents in use is shown in figure 4. Five sets of reagents (ECA prothrombin buffer, ECA-H substrate and ECA ecarin reagent) were tested on 12 different days. Reagents were stored at $37^{\circ} \mathrm{C}$ in the coagulation analyzer for the time of measurement, at least for $3 \mathrm{~h}$ daily and at $4-8^{\circ} \mathrm{C}$ in the intermediate time. Figure 4 shows that the reagents were stable after dissolution for 11 days, whereas on day 12, the measured hirudin concentrations decreased.

The influence of the plasma prothrombin level on ECA and ECT was investigated; results are given in figure 5. Plasma containing a prothrombin level of about $200 \%$ was prepared by addition of $80 \mu \mathrm{g}$ of human prothrombin to $1 \mathrm{ml}$ of pooled plasma; plasma containing prothrombin levels between 0 and $75 \%$ was prepared using factor-IIdeficient plasma and mixtures thereof with pooled plas- ma. The samples were spiked with different amounts of hirudin. The ECA was shown to be absolutely independent of the plasma prothrombin level and can be carried out even in prothrombin-deficient plasma. The ECT test was impracticable in prothrombin-deficient plasma samples. Even plasma prothrombin levels of less than $75 \%$ resulted in the prolongation of the ECT and falsely high hirudin concentrations. The error increases with increasing hirudin levels (fig. 5).

Figure 6 shows the influence of plasma fibrinogen content on ECA and ECT, respectively. Heat-defibrinated plasma and mixtures thereof with pooled plasma were used. An elevated fibrinogen level of about 300\% ( $8.9 \mathrm{~g} / 1$ fibrinogen measured) was prepared by adding human fibrinogen to pooled plasma. Using different amounts of hirudin, no influence of the fibrinogen level on ECA and only a moderate influence on ECT could be observed. In fibrinogen-enriched plasma, there is a decrease in hirudin recovery of about $20 \%$, and in plasma with a fibrinogen content of $25 \%$ of the normal pooled plasma, there is an increase in hirudin recovery of about $30 \%$ using ECT. Due to its principle of measurement, the ECT test was impracticable in fibrinogen-free plasma samples.

The usability of the ECA for the determination of direct thrombin inhibitors other than hirudin was tested 


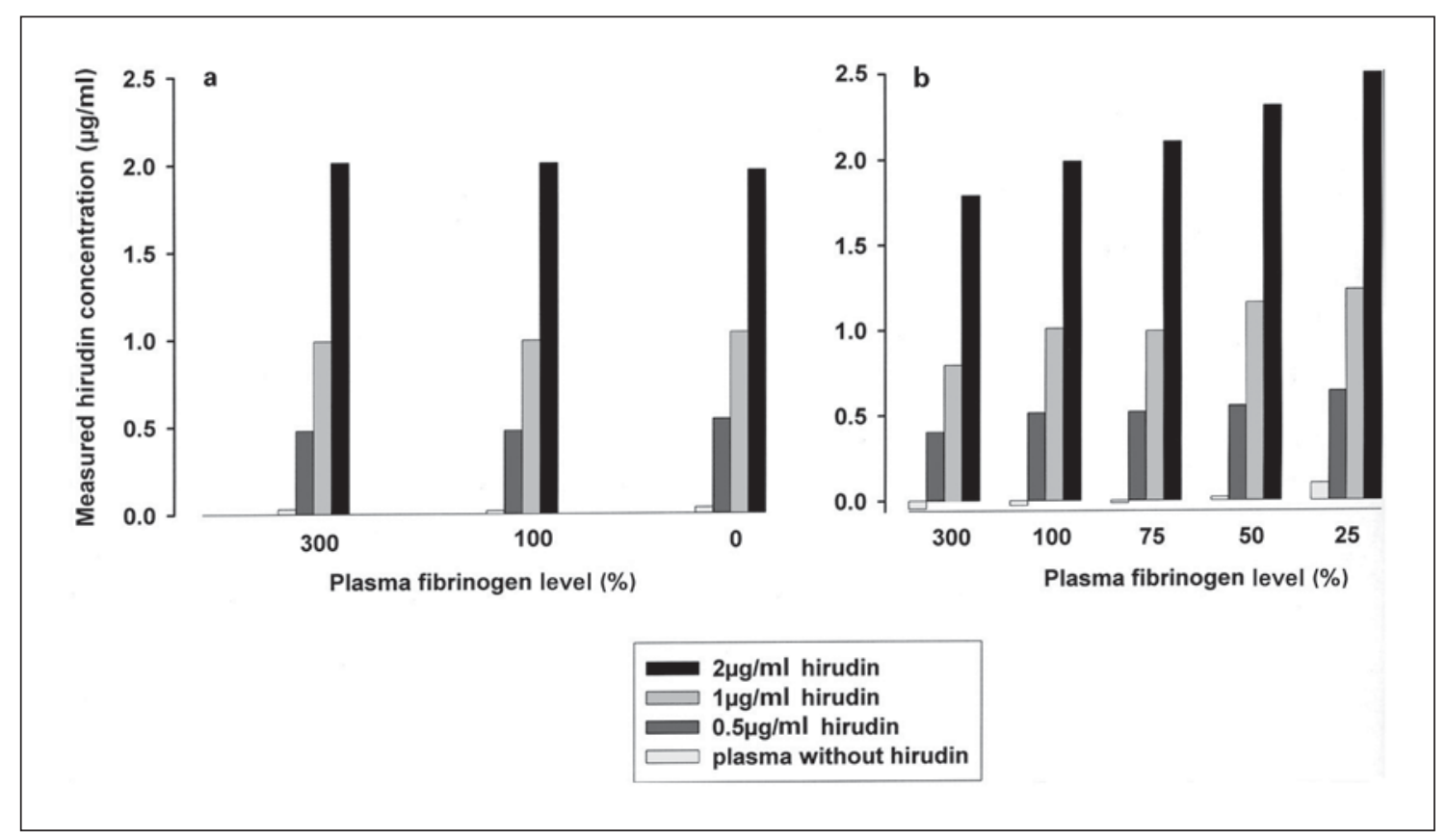

Fig. 6. Influence of the plasma fibrinogen level on hirudin determination using ECA (a) and ECT (b). Data were acquired on TEChrom IV plus; $\mathrm{n}=3$.

Fig. 7. Reference curve of quantitative determination of argatroban using ECA. Data were acquired on Coatron $\mathrm{M} 2 ; \mathrm{n}=30$, mean values and SD are given.

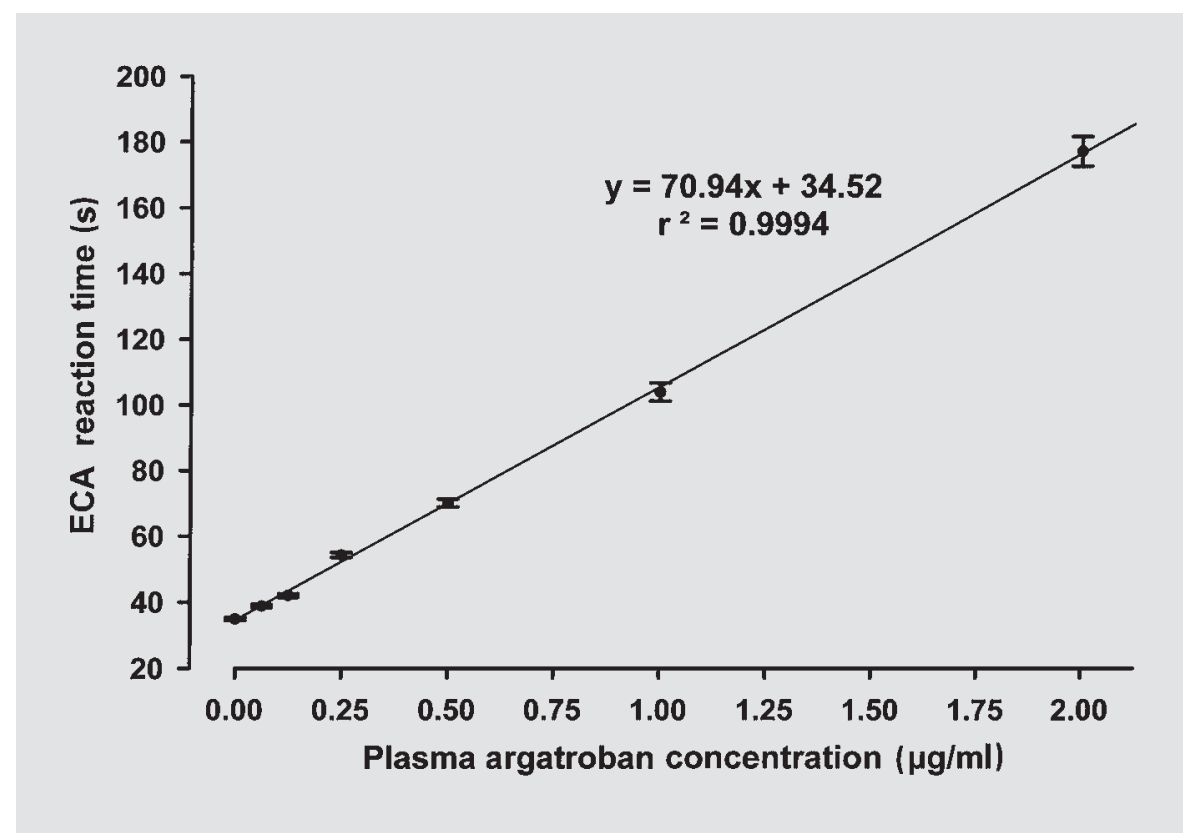

using the small synthetic inhibitor argatroban. For the reference curve, pooled human plasma was spiked with different amounts of argatroban and measured using the ECA-T method (fig. 7). Imprecision data are given in table 2 . There is a clear linear correlation between argatro- ban concentrations tested and ECA reaction time. The accuracy reported as percent recovery is very high in the concentration range between 0.5 and $2 \mu \mathrm{g} / \mathrm{ml}$, and becomes somewhat lower at argatroban concentrations below $0.5 \mu \mathrm{g} / \mathrm{ml}$. 
Table 2. Imprecision data of ECA on Coatron M2 2-channel coagulation analyzer for argatroban determination in plasma

\begin{tabular}{lcccccc}
\hline \multicolumn{7}{c}{ Added amount of argatroban, $\mu \mathrm{g} / \mathrm{ml}$} \\
& 0.062 & 0.125 & 0.250 & 0.500 & 1.000 & 2.000 \\
\hline & 30 & 30 & 30 & 30 & 30 & 30 \\
Number of replicates & 0.075 & 0.119 & 0.291 & 0.513 & 0.986 & 2.009 \\
Mean, $\mu \mathrm{g} / \mathrm{ml}$ & 0.0067 & 0.0076 & 0.0107 & 0.0172 & 0.0384 & 0.0626 \\
$\mathrm{SD}, \mu \mathrm{g} / \mathrm{ml}$ & 9.0 & 6.4 & 3.7 & 3.4 & 3.9 & 3.1 \\
$\mathrm{CV}, \%$ & 0.064 & 0.106 & 0.272 & 0.485 & 0.910 & 1.920 \\
Minimum, $\mu \mathrm{g} / \mathrm{ml}$ & 0.089 & 0.135 & 0.311 & 0.549 & 1.048 & 2.183 \\
Maximum, $\mu \mathrm{g} / \mathrm{ml}$ & 119.3 & 95.2 & 116.4 & 102.6 & 98.6 & 100.5 \\
Recovery, $\%$ & 0.020 & & & & & \\
Detection limit, $\mu \mathrm{g} / \mathrm{ml}$ & 0.061 & & & & & \\
Quantitation limit, $\mu \mathrm{g} / \mathrm{ml}$ & & & & & & \\
\hline
\end{tabular}

\section{Discussion}

For clinical monitoring of hirudin, the manufacturers recommend aPTT. However, it has been shown by many investigators that aPTT is not suited for quantitative hirudin determination because all aPTT assays become less responsive at increasing hirudin concentrations; therefore, toxic blood levels cannot be detected or prevented by measuring aPTT. Further limitations are the dependence of aPTT on the reagent used and the high interindividual variations of the clotting time values $[1,2,17,18]$.

From the variety of methods tested regarding their suitability for monitoring hirudin or other direct thrombin inhibitors, ECT and chromogenic substrate-based assays turned out as tests which can represent the clinical situation more adequately than aPTT $[17,18]$. Especially the ECT test is considered as a fast, highly sensitive and precise method allowing hirudin determination over a wide concentration range with low interindividual variations [20].

The chromogenic substrate assays for hirudin determination described so far are based on the inhibition of thrombin, added in excess to the diluted sample, by hirudin. Residual thrombin is determined by measuring its amidolytic activity towards a chromogenic substrate [9, 11-13]. The ECT and our new chromogenic assay ECA are based on meizothrombin generation from prothrombin by ecarin, a snake venom metalloprotease from Echis carinatus [16, 21, 22]. Direct thrombin inhibitors like hirudin immediately bind to the permanently formed meizothrombin in a concentration-dependent fashion [23]. In the ECT test, the proteolytic activity of noninhibited generated meizothrombin is quantified by measuring the conversion of fibrinogen to fibrin, i.e. the clotting time. In the ECA, the amidolytic activity of meizothrombin towards a chromogenic substrate is determined. The comparison of both meizothrombin-generation-based tests ECT and ECA with the thrombin-based chromogenic assay shows that both tests, ECT and even more ECA, are superior to the thrombin-based chromogenic assay regarding sensitivity and precision at hirudin concentrations in the lower range. The sensitivity of the thrombin-based chromogenic assay is insufficient at low hirudin concentrations. It can be improved by increasing the sample volume, but this will result in loss of linearity of the reference curve.

In chromogenic substrate assays for hirudin determination based on the inhibition of added thrombin, heparin or endogenous heparin-like substances can interfere; consequently, a heparin inhibitor has to be added $[9,11-$ 13]. Heparin alone or complexed to antithrombin III cannot inhibit meizothrombin [24]; therefore, ECA as well as ECT are not influenced by heparin.

Limitations of ECT are its dependence on the plasma fibrinogen level as it is a clotting assay and its dependence on the plasma prothrombin level due to the principle of measurement [20, 25]. ECA overcomes both drawbacks. Whereas in the clotting assay ECT, the prothrombin of the plasma sample is used as a substrate for ecarin, in the ECA, human prothrombin is an internal component of the ECA prothrombin buffer. Therefore, the prothrombin level of the plasma sample does not influence the ECA. Because it is not a clotting assay, the fibrinogen content does not influence the ECA.

The ECA kit consists of only three components, their stability allowing to keep them in the coagulation analyzer at $37^{\circ} \mathrm{C}$ during the measurement, and therefore, incubation times of $30 \mathrm{~s}$ or $1 \mathrm{~min}$ are sufficient. Because of 
the simple test procedure, the ECA can be easily performed both as point-of-care test on manual coagulation analyzers provided with an option for optical measurement and as fully mechanized assay on automated systems [26]. The high level of precision permits each ECA analysis to be carried out as a single determination.

ECA is suitable for quantitative determination of direct thrombin inhibitors other than hirudin. This was shown for argatroban, a synthetic small molecule that selectively inhibits the catalytic site of thrombin in a revers- ible manner [27]. There is a clear linear relationship between inhibitor concentration and ECA reaction time, which makes the ECA more recommendable for quantitative argatroban determinations than other suggested methods, e.g. aPTT or prothrombinase-induced clotting time [27, 28].

It can be concluded that ECA is a simple, rapid, precise, reliable and specific assay for the quantitative determination of direct thrombin inhibitors that is suitable as manual or automated diagnostic test.

\section{References}

-1 Tripodi A, Chantarangkul V, Arbini AA, Moia M, Mannucci PM: Effects of hirudin on activated partial thromboplastin time determined with ten different reagents. Thromb Haemost 1993; 70:286-288

2 Nurmohamed MT, Berckmans RJ, MorrienSalomons WM, Berends F, Hommes DW, Rijnierse JJ, Sturk A: Monitoring anticoagulant therapy by activated partial thromboplastin time: Hirudin assessment. An evaluation of native blood and plasma assays. Thromb Haemost 1994; 72:685-692.

-3 Cullberg M, Eriksson UG, Larsson M, Karlsson MO: Population modelling of the effect of inogatran, a thrombin inhibitor, on ex vivo coagulation time (APTT) in healthy subjects and in patients with coronary artery disease. $\mathrm{Br} \mathrm{J}$ Clin Pharmacol 2001;51:71-79.

-4 Despotis GJ, Hogue CW, Saleem R, Bigham M, Skubas N, Apostolidou I, Qayum A, Joist JH: The relationship between hirudin and activated clotting time: Implications for patients with heparin-induced thrombocytopenia undergoing cardiac surgery. Anesth Analg 2001; 93:28-32.

$\checkmark 5$ Reid TJ 3rd, Alving BM: A quantitative thrombin time for determining levels of hirudin and hirulog. Thromb Haemost 1993;70:608-616.

-6 Spinner S, Stoffler G, Fink E: Quantitative enzyme-linked immunosorbent assay (ELISA) for hirudin. J Immunol Methods 1986;87:7983.

7 Spinner S, Scheffauer F, Maschler R, Stoffler G: A hirudin catching ELISA for quantitating the anticoagulant in biological fluids. Thromb Res 1988;51:617-625.

$>8$ Iyer L, Adam M, Amiral J, Fareed J, Bermes E Jr: Development and validation of two enzyme-linked immunosorbent assay (ELISA) methods for recombinant hirudin. Semin Thromb Hemost 1995;21:184-192.
-9 Griessbach U, Stürzebecher J, Markwardt F: Assay of hirudin in plasma using a chromogenic thrombin substrate. Thromb Res 1985; 37:347-350.

10 Stürzebecher J: Methods for determination of hirudin. Semin Thromb Hemost 1991;17:99102.

11 Spannagl M, Bichler J, Birg A, Lill H, Schramm W: Development of a chromogenic substrate assay for the determination of hirudin in plasma. Blood Coagul Fibrinolysis 1991;2:121-127.

12 Groetsch H, Damm D, Ben Youssef R, Haertel D: Comparison of two different methods for the determination of rDNA-hirudin in plasma samples: HPLC vs a chromogenic thrombin substrate. Thromb Res 1991;64:273-277.

-13 Hafner G, Fickenscher K, Friesen HJ, Rup precht HJ, Konheiser U, Ehrenthal W, Lotz J, Prellwitz W: Evaluation of an automated chromogenic substrate assay for the rapid determination of hirudin in plasma. Thromb Res 1995;77:165-173.

14 Calatzis A, Spannagl M, Gempeler-Messina P Kolde HJ, Schramm W, Haas S: The prothrombinase-induced clotting test: A new technique for the monitoring of anticoagulants. Haemostasis 2000;30(suppl 2):172-174.

15 Nowak G, Bucha E: A new method for the therapeutic monitoring of hirudin. Thromb Haemost 1993;69:306-310.

16 Nowak G: Monitoring of the action of antithrombin agents by ecarin clotting time; in Pifarré R (ed): New Anticoagulants for the Cardiovascular Patient. Philadelphia, Hanley \& Belfus, 1997, pp 539-550.

17 Nowak G: Clinical monitoring of hirudin and direct thrombin inhibitors. Semin Thromb Hemost 2001;27:537-541.

18 Hafner G, Roser M, Nauck M: Methods for the monitoring of direct thrombin inhibitors. Semin Thromb Hemost 2002;28:425-430.
19 Ratnoff OD, Menzie C: A new method for the determination of fibrinogen in small samples of plasma. J Lab Clin Med 1954;37:316-320.

20 Nowak G, Bucha E: Quantitative determination of hirudin in blood and body fluids. Semin Thromb Hemost 1996;22:197-202.

21 Morita T, Iwanaga S, Suzuki T: The mechanism of action of bovine prothrombin by an activator isolated from Echis carinatus venom and characterization of the new active intermediates. J Biochem (Tokyo) 1976;79:1089_ 1108.

22 Rhee MJ, Morris S, Kosow DP: Role of meizothrombin and meizothrombin-(des F1) in the conversion of prothrombin to thrombin by the Echis carinatus venom coagulant. Biochemistry 1982;21:3437-3443.

23 Cote HC, Stevens WK, Bajzar L, Banfield DK, Nesheim ME, MacGillivray RT: Characterization of a stable form of human meizothrombin derived from recombinant prothrombin (R155A, R271A, and R284A). J Biol Chem 1994;269:11374-11380.

24 Schoen P, Lindhout T: The in situ inhibition of prothrombinase-formed human alphathrombin and meizothrombin (des F1) by antithrombin III and heparin. J Biol Chem 1987; 262:11268-11274.

25 Lindhoff-Last E, Piechottka GP, Rabe F, Bauersachs R: Hirudin determination in plasma can be strongly influenced by the prothrombin level. Thromb Res 2000;100:55-60.

26 Lange U, Wiesenburg A, Olschewski A, Nowak G, Bucha E: Quantitative determination of direct thrombin inhibitors using the ecarin chromogenic assay (ECA) - both POCT and automated method. Ann Hematol 2003;82 (suppl 1):S53.

27 Kathiresan S, Shiomura J, Jang IK: Argatroban. J Thromb Thrombolysis 2002;13:41-47.

28 Fenyvesi T, Jörg I, Harenberg J: Monitoring of anticoagulant effects of direct thrombin inhibitors. Semin Thromb Hemost 2002;28:361368 . 